\title{
A rare presentation you want to remember!
}

\author{
Stéphane Bolduc, MD, FRCSC; Julie Couture, MD
}

See related article on page 393.

Can Urol Assoc J 2010;4(6):397-8

$\mathrm{T}$ he literature on undescended testis (UDT) mainly concentrates on the increased risks of infertility and development of germ cell tumours. ${ }^{1}$ Contemporary articles on pediatric testicular problems often poorly address this issue and sometimes neglect it. Not unexpectedly, there is not enough awareness among physicians or parents on this urological emergency; unfortunately in most cases, the diagnosis is deferred.

Undescended testis also appears to be at higher risk for torsion compared to the normally descended testis; this issue is relatively poorly addressed. Gharbi and colleagues present an important review of this poorly appreciated topic, ${ }^{2}$ especially if the risk of torsion is 10 times higher for UDT. ${ }^{3}$ The risk of torsion in an UDT clearly needs to be made more evident to pediatric urologists and pediatricians, as approximately $2 \%$ of all males have UDT. The poor testis salvage rate in this series $(40 \%)$ and in others $(10 \%)^{4-5}$ reflects the late diagnosis resulting from lack of awareness of the risk of torsion in an UDT. This observation becomes even more relevant if the UDT is present in a severely handicapped child or in a child with intellectual disabilities, like Down's syndrome, where UDT can occur in up to $50 \%$ of children. ${ }^{6}$

Clinical symptoms mainly include the appearance of inguinal swelling and erythema described as a tender, firm mass palpated in the groin region. Abdominal pain can be present if the UDT is intra-abdominal. It is usually accompanied by inconsolable crying in infants, poor nutritional intake and occasional vomiting in older children and an empty ipsilateral hemiscrotum. The use of a Doppler ultrasound for the detection of torsion of an inguinal testis has been well-documented, but might be technically more challenging. The management of torsed testis is by immediate surgical exploration, regardless of the location of the testis. Following detorsion, the question is to mobilize the testis and perform scrotal orchidopexy or postpone this definitive surgical treatment. Another somewhat controversial point is whether prophylactic fixation of the contralateral testis

is indicated. It is noteworthy that patients with a history of cryptorchidism who have undergone orchidopexy rarely present with acute scrotum due to torsion. ${ }^{7}$ It seems that evertion of the tunica vaginalis during orchidopexy for UDT, as well as division of the cremasteric fibers, is essential to decrease the risk of future torsion. On the other hand, others believe that orchidopexy of the contralateral testis represents an unnecessary intervention that could modify the anatomy and perhaps increase the risk of torsion. ${ }^{8}$ It is also important to note that because many reports mention the presence of a testicular tumour found at surgery, a high index of suspicion in patients 10 years and older necessitates the dosage of usual testicular tumour makers.

With the modern tendency for earlier orchidopexy, we suspect that these figures cited from historical series have not been updated and probably represent an overestimation of the current incidence. This fact might be balanced by the current increased incidence of prematurity, a known risk factor for UDT. But in a recent report, Kokorowski and colleagues reported that in the last few years, only 50\% of patients with UDTs operated on in the United States underwent surgery before the age of 2 years. ${ }^{9}$ Therefore, the prevention of testicular torsion in UDT must begin with an earlier diagnosis of the UDT and referral, and the waiting list for the orchidopexy should also be reasonable for the urologist.

Finally, we all need to start reminding our referring pediatricians and ourselves that the parents of any child seen with an UDT need to be informed that the development of any tenderness associated with the UDT means an emergent consultation to an emergency room for evaluation; hopefully earlier care results in more salvage of UDTs that twist. When we increase the awareness of this entity among urologists and pediatricians, we should be able to improve testis salvage.

Division of Urology, Centre Hospitalier Universitaire de Québec, Centre hospitalier de I'Université Laval, Québec, QC

Competing interests: None declared. 
This paper has been peer-reviewed.

\section{References}

1. Lee PE. Fertility after cryptorchidism: epidemiology and other outcome studies. Urology 2005;66:427-31.

2. Gharbi $M$, Amri N, Chambeh W, et al. Les torsions sur testicules cryptorchides [article in French]. Can Urol Assoc J 2010;6:393-6.

3. Williamson RCN. Torsion of the testis and allied conditions. Br I Surg 1976;63:465-76.

4. Zilberman D, Inbar Y, Heyman Z, et al. Torsion of the cryptorchid testis-can it be salvaged? J Urol 2006; 175:2287-9.

5. Osifo DO, Osaigbovo E0. The prevalence, postnatal descent, and complications of undescended testes among children who underwent neonatal circumcision in Benin City, Nigeria. J Pediatr Surg 2009;44:791-6.
6. Papatsoris AG, Mpadra F, Karamouzis M, et al. Torsion of undescended testis in a man with Down's syndrome. Int J Urol 2003; 10:233-5.

7. Nesa, S, Lorge F, Wese FX, et al. Testicular torsion after previous orchidopexy for undescended testis. Acta Urol Belg 1998;66:25-6.

8. Domínguez Hinarejos C, Vivancos Garbayo S, Bonillo García MA, et al. Torsion of undescended testis. Actas Urol Esp 2007;31:49-51.

9. Kokorowski PJ, Routh JC, Graham DA, et al. Variations in timing of surgery among boys who underwent orchidopexy for cryptorchidism. Pediatrics 2010;126:e576-82.

Correspondence: Dr. Stéphane Bolduc, Centre hospitalier de l'Université Laval, 2705, boul. Laurier, Québec, QC GIV 4G2; fax: 418-654-2137; sbolduc_2002@yahoo.ca 